\title{
IMPLEMENTING A SOUTH AFRICAN E-DISPUTE RESOLUTION SYSTEM FOR CONSUMER DISPUTES
}

\author{
Sershiv Reddy \\ LLB LLM \\ Admitted Attorney \\ Lecturer, Department of Mercantile Law \\ University of Johannesburg
}

\section{SUMMARY}

In the 1990s, online dispute resolution became more prevalent with the growth of the Internet and its accompanying issues. Yet despite the apparent advantages of online dispute resolution platforms, South Africa has lagged behind in using such a system for consumer disputes. It has become necessary to appeal for the use of an online system since courts are often too costly and backlogged with other disputes; and existing consumer mechanisms found in the Consumer Protection Act 68 of 2008 have proved to be ineffectual. With the expansion of artificial intelligence and South Africa now entering the Fourth Industrial Revolution, it is evident that reforms to consumer laws may be necessary to keep up with technological advances, as well as to expedite consumer disputes. The use of an online dispute resolution system powered by artificial intelligence may prove beneficial in South Africa. This article argues for the implementation of an e-dispute resolution system similar to eBay's online Resolution Center.

\section{1}

\section{INTRODUCTION}

The objective of this research is to argue for the implementation of an online dispute resolution system using artificial intelligence (AI) to assist and resolve consumer disputes. The need for this stems from the high cost and slow processes of litigation that burden many consumers. Courts have acknowledged that disputing parties should be encouraged to avoid litigation, rather than prematurely instituting action in court as a first option, as it is costly and often unnecessary. ${ }^{1}$ Furthermore, there are instances where the claim brought by a consumer is small and the litigation costs exceed the relief claimed. ${ }^{2}$ Authors have argued that online disputes between suppliers and consumers are primarily concerned with claims that are small in monetary value; but there is a high volume of such disputes, and

Continuous Oxygen Suppliers (Pty) Ltd t/a Vital Aire v Meintjes (2012) 33 ILJ 629 (LC) par 22.

2 OECD "Consumer Dispute Resolution and Redress in the Global Marketplace" 2006 https://www. oecd.org/sti/consumer/36456184.pdf (accessed 2020-03-02). 
therefore a unique system of dispute resolution is required for these cases. ${ }^{3}$ In reality, regardless of whether a transaction originated online or offline, consumer disputes may arise over small amounts of money. An online dispute resolution system would therefore be available to consumers who enter into both online and offline transactions and would require mediation to reach a simple resolution. The motivating factors for creating and using such a system appear to centre on money, efficiency and convenience. 4

In this context, it should be noted that South Africa has introduced the Consumer Protection Act $^{5}$ (CPA). From the first few sentences of the Preamble, it is clear that it embraces a consistent legislative and enforcement framework relating to consumer transactions and agreements to ensure accessible, transparent and efficient redress for consumers who have been abused or exploited in the marketplace. ${ }^{6}$ Although the CPA provides several relevant mechanisms and sets out the procedures for consumer redress, it is submitted that an online system is needed in the context of the technological era. This need is apparent in today's commercial world; the South African legal system can choose to rely on traditional dispute resolution methods that have been in existence for many years, or find a new system that is better suited to e-commerce. ${ }^{7}$ Even where retailers provide online platforms or online customer services to resolve simple consumer issues, a formal online system may be implemented to ensure the satisfactory resolution of consumer disputes, as well as provide a uniform regulatory approach and ensure compliance with consumer laws. The advent of the Fourth Industrial Revolution and artificial intelligence technologies give countries opportunities to improve their economies through the use of digital technologies. ${ }^{8}$ Online dispute resolution may be considered as one of these opportunities.

The issue here is whether establishing a South African online dispute mechanism would offer an efficient and effective system to resolve legal consumer disputes, especially for those claims that are not high in value. The idea would be to create an online dispute resolution (ODR) process, including an e-dispute system that could potentially expedite both offline and online consumer claims. The e-dispute system would enhance the current redress framework envisaged in the CPA by providing consumers with an online alternative to resolving disputes by mediation. The system would

3 Stegner "Online Dispute Resolution: The Future of Consumer Dispute Resolution?" 2017 Yearbook on International Arbitration 347348 . The author submits that the average online consumer transaction is approximately 100 euros. In the South African context, if consumers spend a few hundred rands on a product, it would seem fruitless to attempt to institute an action in court to retrieve this amount. The cost outweighs the benefit and it is not worth pursuing such small transactions. As Stegner argues that these small disputes are common, a system needs to be established where consumers can bring their small claims without high litigation costs.

4 Condlin "Online Dispute Resolution: Stinky, Repugnant, or Drab" 2017 Cardoza Journal of Conflict Resolution 717 720-721.

68 of 2008.

See the title of the Act read with par $(b)$ of the Preamble.

Cortes Online Dispute Resolution for Consumers in the European Union (2010) 2.

8 Pollitzer "Creating a Better Future: Four Scenarios for How Digital Technologies Could Change the World" 2019 Journal of International Affairs 7576. 
make use of $\mathrm{Al}$ algorithms to seek a fair resolution for the disputing parties. Although the system would be powered by $\mathrm{Al}$, human intervention would also be required to ensure a fair and effective process for consumers. eBay has proved that an online dispute resolution centre controlled by artificial intelligence can be a simple and effective system to use for disputes; South Africa may learn from this type of model. Where such an e-dispute system fails to resolve the matter, it may then assist consumers by referring them to the other normal redress mechanisms as provided in the CPA.

\section{THE EXISTING DISPUTE PROCESS IN THE CPA}

It is necessary briefly to examine the existing redress mechanisms provided for consumers in terms of the CPA in order to assess their adequacy in resolving consumer disputes. Probably hundreds, if not thousands, of consumer complaints occur on a daily basis. According to Romualdi, high levels of civil litigation coupled with limited human resources can lead to excessive delays in resolving consumer disputes. ${ }^{9}$ In this context, it is submitted that consumer complaints that are frivolous waste the courts' time and scarce resources. As already mentioned, some claims may be for small monetary amounts, and normal civil remedies and litigation costs may outweigh the claim sought. As a consequence of high costs and confusing or slow processes, consumers may be left with unresolved disputes. Du Plessis submits that unresolved disputes between consumers and suppliers undermine the maintenance of social order. ${ }^{10}$ An effective redress mechanism is therefore imperative in any legal system to ensure that consumers obtain adequate redress for their legitimate complaints.

In terms of South African consumer law, if consumers wish to resolve their disputes, they should follow the procedures as set out in the CPA. The CPA aims to promote consumer empowerment through awareness and education, while at the same time also providing consumers with an efficient and accessible means of dispute resolution. ${ }^{\top}$ The Act sets out various avenues that consumers may pursue should they have a grievance against a supplier. The Act further empowers consumers to enforce their consumer rights using the available mechanisms as provided for in the CPA. Consumers therefore have at their disposal different procedures to enforce their consumer rights, depending on the relief sought. Chapter 3 of the CPA deals with the protection of consumer rights and the consumer's voice; Part $A$, in particular, focuses on the consumer's right to be heard and to obtain redress. This ensures that consumer disputes are brought in the correct forum to receive the correct relief.

The avenue that consumers should first pursue is that of alternate dispute resolution. Traditionally, disputes have involved litigation, which required parties to resolve their issues in court. However, alternative dispute

\footnotetext{
9 Romualdi "Problem-Solving Justice and Alternative Dispute Resolution in the Italian Legal Context" 2018 Utrecht Law Review 52.

10 Du Plessis "Enforcement and Execution Shortcomings of Consumer Courts" 2010 SA Merc LJ 517529

11 S $3(f)-(g)$ CPA.
} 
resolution seeks to resolve disputes without the need to go to court. ${ }^{12}$ Bearing in mind that alternative dispute resolution may use mediation to resolve disputes between parties, the process intends finding an amicable agreement between the parties with the assistance of a neutral and impartial third party mediator. ${ }^{13}$ Other than reaching an amicable solution, it may also offer a cheaper and quicker avenue than use of the courts. The idea behind alternative dispute resolution is therefore to provide a less expensive and less complicated means of redress for consumers than is provided by court procedures. ${ }^{14}$ Alternative dispute resolution seeks to avoid the court process and its related constraints, such as costs, knowledge and time, which may even cause consumers to withdraw their claims and impede access to justice. ${ }^{15}$ Furthermore, in terms of the CPA, if consumers approach the Commission or Tribunal directly, they will usually first be referred to an alternative dispute resolution agent to address their problem. ${ }^{16}$ More importantly, the CPA also states that a consumer must first pursue and exhaust all other avenues as provided in the Act, before approaching a court with jurisdiction over the matter. ${ }^{17}$ These provisions indicate that alternative dispute resolution is therefore the preferred mechanism for use in resolving consumer disputes.

The CPA specifically advocates for alternative dispute resolution in section 70 , which provides that the consumer may refer his or her complaint to an ombud with jurisdiction, an industry-accredited ombud, a person or entity that provides conciliation, arbitration or mediation services, or a consumer court. ${ }^{18}$ The Office of Consumer Goods and Services Ombud has been set up in terms of the CPA and is tasked with receiving and dealing with consumer goods and services complaints free of charge. ${ }^{19}$ An advantage of the alternative dispute resolution process is that where it successfully resolves the consumer's complaint, the alternative dispute resolution agent may record the resolution in the form of an order and if the parties to the dispute consent to the order, it can be sent to the Tribunal or High Court to be made a consent order, which may include an award of damages in favour of the aggrieved consumer. ${ }^{20}$

If, however, the complaint cannot be resolved through one of the alternative dispute resolution agencies, the agent may file the consumer's complaint with the Commission. ${ }^{21}$ The Commission is responsible for receiving complaints from consumers about alleged contraventions of the

12 Barnett and Treleaven "Algorithmic Dispute Resolution: The Automation of Professional Dispute Resolution Using Al and Blockchain Technologies" 2018 The Computer Journal 399 400-401.

13 Romualdi 2018 Utrecht Law Review 5256.

14 Woker "Consumer Protection and Alternative Dispute Resolution" 2016 SA Merc LJ 2126. Although dispute resolution may well provide an alternate form of redress, in certain instances consumers may still need to approach courts for appropriate relief.

15 Hanriot "Online Dispute Resolution (ODR) as a Solution to Cross Border Consumer Disputes: The Enforcement of Outcomes" 2015 McGill Journal of Dispute Resolution 15.

S 69 CPA.

S 69(d) CPA.

S 70(1)(a)-(d) CPA

See Consumer Goods and Services Ombud http://www.cgso.org.za/19-08-2016.

S 70(3)(a)-(b) \& (4) CPA

S 70(2) CPA. 
Act by businesses. ${ }^{22}$ When the Commission receives a complaint, it may issue the consumer with a notice of non-referral if the complaint appears to be frivolous or vexatious, does not allege any facts that would grant any remedy in terms of the CPA, or the claim has prescribed. ${ }^{23}$ After investigating the consumer's complaint, the Commission has other alternatives available, including referring the matter to the National Prosecuting Authority, and if the Commission believes a business has engaged in prohibited conduct, it can refer the matter to the Equality Court, propose a draft consent order, or issue a compliance notice in terms of the Act. "Prohibited conduct" is broadly defined as an act or omission in contravention of the CPA.

Should the Commission reasonably believe that the consumer's complaint involves prohibited conduct, it can issue a compliance notice against the business. ${ }^{26}$ The compliance notice will inform the business, among other things, of the provision of the CPA that has not been complied with, the nature and extent of the non-compliance and the penalty that has been imposed. ${ }^{27}$ If the business fails to comply with the notice issued, then the Commission can apply to the Tribunal for the imposition of an administrative fine. ${ }^{28}$ Businesses should be wary of these fines as they are quite high but may not exceed the greater of 10 per cent of the respondent's annual turnover during the preceding financial year or R1 $000000 .^{29}$ The Commission can also refer the matter to the Tribunal or, if it has issued the consumer with a non-referral notice, the consumer can apply to the Tribunal with leave of the Tribunal. ${ }^{30}$ An aggrieved consumer should only seek relief from court as a last resort when all other remedies available to the consumer as listed above have been exhausted. ${ }^{31}$

What the procedure in the CPA illustrates is that consumers have been given several avenues to pursue when enforcing their rights. The process, however, seems convoluted and time-consuming. A further critique of the existing framework in the CPA reveals several weaknesses of the Commission, which explain why it has failed as a mechanism to protect consumers. Some of the weaknesses identified include lack of clear processes, inaccessibility of the Commission by consumers, high work load, low work output, differing interpretations of the CPA by the Commission, and poor reputation owing to negative publicity. ${ }^{32}$ Despite having several avenues to pursue their claims, consumers may not pursue these avenues because of the length of time or the costs involved in obtaining redress. Thus it has been argued that although the CPA has in theory provided

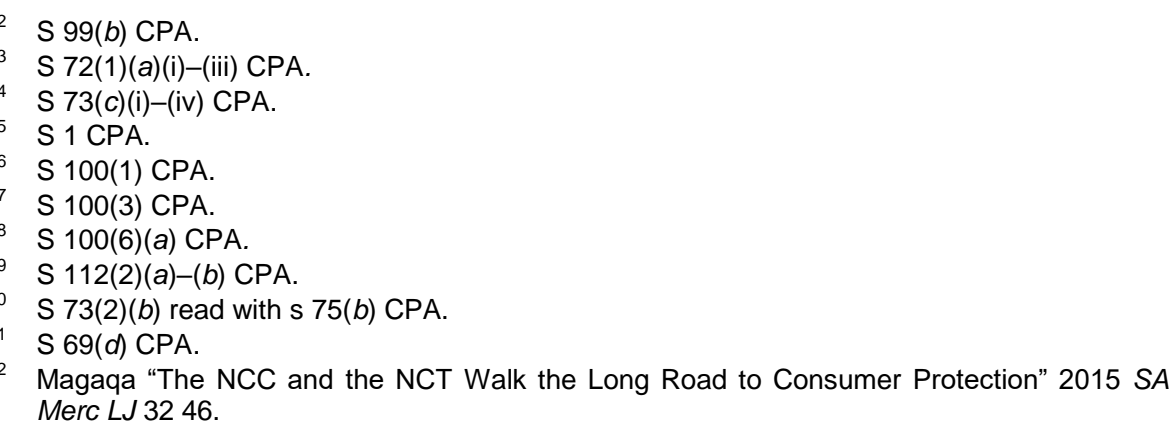


consumers with efficient redress mechanisms, these mechanisms in practice have not been successful. Several erroneous decisions made by the National Consumer Commission (owing to its failure to understand the Act) has had the effect of creating obstacles to the successful implementation of the Act. ${ }^{33}$ Consumers may therefore not have confidence that their claims will be satisfied because the protective consumer bodies themselves do not adequately apply the provisions of the CPA. These weaknesses are attributed to the efficacy of the Commission; if these issues were resolved, the Commission could become a powerful and valuable protection body for consumers. According to a news report in the latter part of 2019, the Commission was reported to be understaffed and admitted that it lacked the necessary resources to investigate every single case and was of the view that it would be more beneficial for disputing parties to resolve their disputes in an amicable manner rather than using the Commission's limited resources. ${ }^{34}$ This news report reveals that the Commission requires more resources and staffing. An amicable resolution of consumer disputes through an online dispute resolution system may help alleviate the Commission's burden of investigating consumer matters.

Consumers may generally rely on normal court processes should they wish to resolve consumer disputes. However, the CPA makes it highly problematic for consumers to approach courts directly. Section 69(d) states that consumers can only approach a court if they have exhausted all other remedies and avenues in terms of the CPA. This means that courts are a consumer's last resort and they may only gain relief after going through the whole dispute process step-by-step as mentioned above. This argument was confirmed in Joyroy 4400 CC $v$ Potgieter, ${ }^{35}$ in which the court stated that section $69(d)$ is clear and unambiguous: the legislature had specifically prescribed the redress for consumers and the courts could only be approached once other avenues for redress had been exhausted. ${ }^{36}$ Naudé argues however, that it is questionable that consumers should be allowed to approach the ordinary courts in the alternative, especially where a claim for damages exists. ${ }^{37}$ In cases that involve small amounts of money, it is unlikely that consumers would even consider bringing an action in court. This is also attributed to the fact that consumers would need to engage the services of attorneys to represent them in court actions and litigation will be an added cost. Mania has argued that the online mediation of disputes saves costs, considering that parties would not require a professional proxy to represent them and would further not require the issuing and serving of

33 Maimela and Swanepoel "Legal Aspects With Regard to Plastic Surgeons in Context of Commercial Advertising" 2015 SA Merc LJ 128142.

34 Omarjee "Consumer Watchdog Laments Understaffing as It Tackles Ford, Unsafe Meat, Timeshare Cases" Fin24 2019 https://www.fin24.com/Economy/consumer-watchdoglaments-understaffing-as-it-tackles-ford-unsafe-meat-timeshare-cases-20191023 (accessed 2020-03-02).

352016 (3) SA 465 (FB).

36 Joyroy $v$ Potgieter supra par 8.

37 Naudé "Enforcement Procedures in Respect of the Consumer's Right to Fair, Reasonable and Just Contract Terms Under the Consumer Protection Act in Comparative Perspective" 2010 SALJ 515526. 
legal documents. ${ }^{38}$ The mechanisms provided for in the CPA are therefore not beneficial to consumers who seek to claim small amounts. Even where the monetary value of a claim is high, consumers may not approach the courts directly.

The current framework is not efficient. Woker alludes to the delays that may occur in the different forums, and states that although it may be appealing to consumers to have different options to pursue their disputes, resolution of these disputes is far from quick. ${ }^{39}$ As a result of these delays and monies spent to institute and pursue their claims, consumers may be deterred from pursuing their claims. ${ }^{40}$ Naudé argues that consumer disputes are likely to be heard in the lower courts where decisions are sometimes unreported; and where matters do fall within the jurisdiction of the High Court, these usually involve disputes over small sums. ${ }^{41}$ The dispute process in the CPA does not appear to be effective. Despite low-cost options to resolve a dispute, there is a need for a quicker and more efficient system. Although approaching a small claims court may also be a viable option to overcome some of these problems, it still requires parties to attend court physically and to follow the normal legal processes of sending a letter of demand and a summons to the wrongdoers; it also places a R20 000 limitation on claims. ${ }^{42}$ The online dispute resolution system may potentially assist consumers in processing their disputes more quickly without the need to attend court physically.

\section{RESOLVING DISPUTES ONLINE}

Consumers have different avenues at their disposal should they require redress. According to the Intergovernmental Group of Experts on Consumer Law and Policy, there are four avenues for consumer redress.

1. Informal avenues: should consumers be aggrieved by certain conduct of a business, they should first seek an informal resolution by directly contacting that business.

2. Voluntary avenues: businesses themselves may have their own dispute resolution processes or platforms, such as eBay's Resolution Center.

3. Statutory avenues: legislation may specify what dispute resolution process to follow should consumers require redress.

4. Judicial avenues: consumers may pursue their claims using the normal court processes, including the small claims court or ordinary civil courts. ${ }^{43}$

38 Mania "Online Dispute Resolution: The Future of Justice" 2015 International Comparative Jurisprudence 7679.

39 Woker "Evaluating the Role of the National Consumer Commission in Ensuring That Consumers Have Access to Redress" 2017 SA Merc LJ 12.

40 Woker 2017 SA Merc LJ 14.

41 Naudé 2010 SALJ 515527.

42 The Department of Justice and Constitutional Development "Small Claims Court" https://www.justice.gov.za/scc/scc.htm (accessed 2020-03-02).

43 Intergovernmental Group of Experts on Consumer Law and Policy "Agenda Item 3d. Dispute Resolution and Redress - Contribution 1" $2018 \mathrm{https}: / /$ unctad.org/meetings/en/ Contribution/cicplp3rd_c_ftc_drr_en1.pdf 1-2 (accessed 2020-03-02). 
The above information proposes that consumers should seek first to resolve their grievances directly with businesses, and resort to dispute resolution where informal avenues fail to prove satisfactory for consumers. With the advancement in technology, South Africa has seen consumer transactions occurring through the Internet. Communications over the Internet using electronic devices have been termed "e-commerce". More specifically " $m$ commerce" applies to the use of mobile devices for commercial transactions. ${ }^{44} \mathrm{~A}$ consequence of consumer transactions is that disputes may arise between consumers and suppliers. Consumers therefore seek to find the fastest and most effective means to resolve their claims, whether these transactions have originated online or offline and court process may not be the most favourable option. Apart from relying on court structures, customer services may take days or weeks to respond to consumer queries on claims, which can be frustrating and may lead to no formal outcome. An online system to resolve consumer disputes is therefore appealing if it will obtain a quicker legal remedy for everyday consumer disputes.

The Internet has become an acceptable commercial trading platform, and has resulted in the growth of e-commerce and the need for an online dispute resolution system. ${ }^{45}$ In the last decade, online consumer transactions have become more common, evidenced by the activities of Takealot.com and eBay.com. As an illustration, eBay had 183 million active online buyers by the last quarter of 2019 , which indicated a growth from previous years. ${ }^{46}$ Furthermore, the same period reflected gross merchandise volume amounting to approximately 23.3 billion US dollars. ${ }^{47}$ Takealot has also been hailed as a successful platform on which consumers may conduct their online shopping. In a study of online retailing in South Africa conducted by Goga, Paelo and Nyamwena, the authors argue that Takealot is one of the largest online platforms used by South African consumers because of the wide range of merchandise it offers. As a consequence, Takealot also had the largest market value and revenue of any online retailer. ${ }^{48}$ This information leads one to believe that online transactions are becoming a more common, competitive and preferred method of transacting among consumers. The rapid increase in use of these online platforms has also led to problems of regulation. Stegner alludes to the fact that online trade has

44 Snail and Papadopoulos Cyberlaw @ SA 3: The Law of the Internet in South Africa (2012) 63.

45 Duca, Rule and Loebl "Facilitating Expansion of Cross-Border E-Commerce: Developing a Global Online Dispute Resolution System (Lessons Derived From Existing ODR Systems: Work of the United Nations Commission on International Trade Law)" 2012 Penn State Journal of Law \& International Affairs 5961.

46 Clement "eBay: Total Active Buyers Worldwide 2010-2019 Number of eBay's Total Active Buyers From 1st Quarter 2010 to 4th Quarter 2019" (2020) https://0-www-statistacom.ujlink.uj.ac.za/statistics/242235/number-of-ebays-total-active-users/ (accessed 202003-02).

47 Clement Statista'eBay: Gross Merchandise Volume 2014-2019 (2020) https://0-wwwstatista-com.ujlink.uj.ac.za/statistics/242267/ebays-quarterly-gross-merchandise-volume-bysales-format/ (accessed 2020-03-02).

48 Goga, Paelo and Nyamwena "Online Retailing in South Africa: An Overview" 2019 CCRED Working Paper 2 https://ssrn.com/abstract=3386008 (accessed 2019-03-02). According to the research provided by these authors, in 2017, Takealot had a turnover of R2.3bn and processed 2.9 million transactions from one million consumers. 
developed and progressed faster than ODR mechanisms. ${ }^{49}$ As a result, Hanriot argues that seeking redress on the Internet in the form of ODR has emerged as a logical solution to resolve the large number of small-value disputes that occur on a daily basis. ${ }^{50}$ It makes sense that if a consumer purchases an item online, a form of redress should be available through an online mechanism. However, the same benefits could be available for offline transactions, in that rather than consumers physically needing to go into retail stores to resolve disputes, they could opt to resolve their disputes using an online platform from the comfort of their homes. ${ }^{51}$

Research has proved that resolving consumer disputes through the Internet may be preferable to utilising the ordinary court processes. Hurter avers that although transacting on the Internet may pose unique and serious problems when deciding how, where, by whom, at what cost, and how effectively a dispute may be resolved, it is clear that the Internet is used because it offers convenience in overcoming the constraints of time and space. $^{52}$ Thompson submits that an ODR system may fill an implementation gap in the justice system by resolving disputes and the new system may also address access-to-justice challenges by using technology as an efficient solution to resolve disputes. ${ }^{53}$ Schmitz highlights the reasons that an ODR system is the way forward, by arguing that consumers do not want to waste time and money on phone calls or the like when there is another fair solution through online dispute resolution, which should entail a simple-toaccess, free service to consumers, and an easy-to-understand system. ${ }^{54}$ Other arguments as to why consumers should avoid traditional court processes focus on transportation issues, confusion about the process, a fear of public speaking or anxiety. ${ }^{55}$ All these arguments illustrate a strong case for an ODR system. Such an online system may be extremely important in South Africa, where many consumers fall within the vulnerable or disadvantaged consumer segment: it would allow them to access justice without proceeding to court. A consumer's financial means play a prominent role in his or her decision whether to pursue legal action in court, which often requires the expertise of a lawyer. The online system would therefore assist the consumers with a simple process to follow that eliminates the need to travel to the courts and alleviate an overflow of complaints being instituted in courts. The online system would be accessible to all consumers regardless

49 Stegner 2017 Yearbook on International Arbitration 347349.

50 Hanriot 2015 McGill Journal of Dispute Resolution 12.

51 Offline customers would arguably save time and costs by avoiding the need to wait in line at customer services in retail stores.

52 Hurter "An Analysis of a New State of the Art South African Online Dispute Resolution System" 2004 SA Merc LJ 779780.

53 Thompson "Creating New Pathways to Justice Using Simple Artificial Intelligence and Online Dispute Resolution" 2015 International Journal of Online Dispute Resolution 45. Thompson argues for an online artificial system to regulate disputes known as the Justice Pathway Expert System (JPES). The system is intended to be used by non-experts who require an alternative and cheaper means to access justice.

54 Schmitz "A Blueprint For Online Dispute Resolution System Design" 2018 Journal of Internet Law 37.

55 Cartwright and Greiling "Court-Connected Online Dispute Resolution Outcomes From Family, Civil, and Traffic Cases in the United States" 2018 International Journal on Online Dispute Resolution 45. 
of their financial means; all that is required is access to the Internet, which nevertheless may be problematic for consumers who live in rural areas.

It is necessary to analyse what an ODR system entails. ODR systems may be described as online Internet-based platforms that enable parties to resolve their disputes. ${ }^{56}$ The notion behind ODR is to use and implement existing forms of alternative dispute resolution through the Internet to resolve disputes. ${ }^{57}$ ODR uses technology to facilitate the resolution of disputes between parties using either negotiation, mediation or arbitration, or a combination of all three; it can be fully automated or involve human intervention. ${ }^{58}$ Originally, ODR focused on resolving disputes that arose online. However, recently the focus has shifted to include non-financial disputes and disputes that did not originate online, but through normal and ordinary physical transactions. ${ }^{59}$ ODR may be divided into two categories: the first category relates to the establishment of specific dispute resolution applications that may be used to resolve online and offline disputes; whereas the second category looks to the future of ODR, using tools that will provide a support system for mediation and arbitration. ${ }^{60}$ This is further explained by Sela, who submits that there are two online dispute resolution systems that may be used. ${ }^{61}$ The first system is an instrumental online dispute resolution system, which involves using an online space for the dispute resolution process, assisting parties with collecting and delivering information in a constructive manner, but the planning, interaction, and decision-making remain in control of the human parties who use the system. ${ }^{62}$ The second system refers to a principal online dispute resolution mechanism that takes a proactive role in facilitating dispute resolution and is typically powered by artificial intelligence to give an automated response. Such an online system may still require natural persons to facilitate its operations or may rely on machines to automate the process.

ODR has become more appealing in the last few years because it represents a more promising solution to disputes than litigation does and may potentially offer a system that is free, simple, efficient, transparent, and fair. ${ }^{63}$ Authors have argued for similar fundamental principles to apply to the online dispute resolution process, such as due process and accountability. ${ }^{64}$ Wing opines that the manner in which an ODR system is designed and

56 Sela "Can Computers Be Fair? How Automated and Human-Powered Online Dispute Resolution Affect Procedural Justice in Mediation and Arbitration" 2018 Ohio State Journal on Dispute Resolution 9193.

57 Mania 2015 International Comparative Jurisprudence 7678.

58 Barnett and Treleaven 2018 The Computer Journal 399400.

59 Zeleznikow "Can Artificial Intelligence and Online Dispute Resolution Enhance Efficiency and Effectiveness in Courts" 2017 International Journal for Court Administration 3035.

60 Rabinovich-Einy and Katsh "Lessons From Online Dispute Resolution for Dispute System Designs" in Wahab, Katsh and Rainey Online Dispute Resolution: Theory and Practice a Treatise on Technology and Dispute Resolution (2012) 3940.

61 Sela 2018 Ohio State Journal on Dispute Resolution 91 99-100.

62 Sela therefore notes that this platform relies on a human third-party to operate it and to communicate with the disputants. Such an online system will still need to be overseen by humans.

63 Hanriot 2015 McGill Journal of Dispute Resolution 13.

64 Stegner 2017 Yearbook on International Arbitration 347359. 
created will determine whether it will magnify the risk of substantive and procedural injustice or create opportunities for access to justice. ${ }^{65}$ In other words, the author suggests that an ODR system may in fact impede access to justice, depending on how it has been set up to manage disputes. Access to an ODR system for all consumers is imperative, especially those who do not have the financial means to pursue ordinary civil remedies. If a system is complicated and costly, it will impede access to justice and will not be a suitable mechanism to use to resolve consumer disputes. Regardless of what online system is used, an ODR system should be based on several key values. Vilalta proposes that an ODR system should be driven by a number of commonly accepted standards and principles, namely:

- private autonomy;

- confidentiality;

- impartiality;

- efficiency (effectiveness in speed and costs);

- transparency; and

- legality. ${ }^{66}$

These principles are further explained by Hurter, who argues that five essential elements or best practices should feature in any ODR system. ${ }^{67}$

1. Time and cost effectiveness: as litigation is often costly, ODR should be a viable alternative to the more traditional court process. Hurter submits that the system should be able to resolve a large number of disputes quickly and at low cost. ${ }^{68}$

2. Privacy and confidentiality: not only should certain information be kept private and confidential, but the whole process itself should also remain private and not be publicised.

3. Transparency: information should be made available to the parties so they understand the risks associated with using the online system and be able to make an informed decision. This also relates to what information will be used or processed when resolving a dispute.

4. Impartiality and independence: this ensures fairness towards both parties by using codes of conduct or other regulatory bodies that adhere to rules and procedures.

5. Effectiveness: this relates to the ease of use of the online system, as well as the success of enforcing its outcomes.

65 Wing "Artificial Intelligence and Online Dispute Resolution Systems Design Lack of Access to Justice Magnified" 2017 International Journal on Online Dispute Resolution 1617 . Wing argues that the ODR system relies heavily on data and there may be risks in collecting and processing the data it receives.

66 Vilalta "ODR and E-Commerce" in Wahab, Katsh and Rainey Online Dispute Resolution: Theory and Practice: A Treatise on Technology and Dispute Resolution (2012) 113126 127.

67 Hurter 2004 SA Merc LJ 779 787-790.

68 Also see Sela 2018 Ohio State Journal on Dispute Resolution 91 93. Online mechanisms may therefore resolve a large number of cases operating in a wide array of legal domains, such as small claims, consumer and commercial disputes and traffic penalties. 
In South African law, the Electronic Communications and Transactions Act ${ }^{69}$ (ECTA) allows for regulations to be published in respect of alternative dispute resolution mechanisms. These regulations, however, only relate to the resolution of disputes in respect of the "za" domain name space. ${ }^{70}$ Despite this restriction, it is submitted that the principles contained in the alternative dispute resolution section of the Act may prove useful for regulating an e-dispute system. The following relevant provisions as extracted from ECTA are useful:

1. the role that the Authority must fulfil in administering the dispute resolution procedure, $7^{71}$

2. the appointment, role and function of dispute resolution adjudicators; ${ }^{72}$

3. the procedure and rules that must be followed in adjudicating disputes; ${ }^{73}$

4. the manner, costs of and time within which a determination must be made $^{74}$

5. the implementation of determinations made in terms of the dispute resolution procedure $;^{75}$ and

6. the enforcement and publication of determinations. ${ }^{76}$

These provisions are highly beneficial for establishing an e-dispute resolution system as they could provide clarity on how the system is to be regulated, especially regarding the costs and time involved in the process of resolving disputes, the legal implications of a decision and the enforcement of outcomes. Privacy also plays a prominent feature in these systems. In terms of South African law, the right to privacy is protected through the common law, legislation and the Constitution. ${ }^{77}$ The right to privacy is protected in terms of the law of delict, the Protection of Information $\mathrm{Act}^{78}$ and section 14 of the Constitution. These standards as argued by authors and as contained in ECTA will be discussed in the e-dispute resolution section below.

It is clear that an ODR system can be beneficial in resolving consumer disputes. However, Cortes argues that ODR systems should only be used for certain types of dispute, such as when parties do not suffer from a great disparity in power and where they wish to resolve the dispute but are unable to meet physically. ${ }^{79}$ In consumer transactions, arguably the supplier has the greater bargaining power. It is submitted that the system should be used for simple disputes even where the parties can meet physically. The whole idea

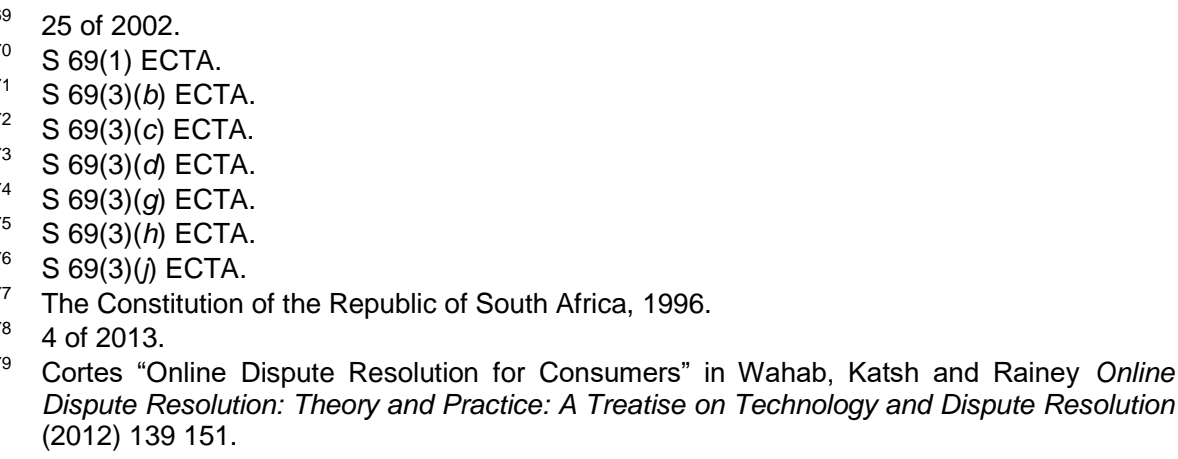

9 Cortes "Online Dispute Resolution for Consumers" in Wahab, Katsh and Rainey Online Dispute Resolution: Theory and Practice: A Treatise on Technology and Dispute Resolution (2012) 139151. 
behind ODR is to provide a more convenient and quicker way to resolve disputes than one requiring consumers to travel to resolve the matter. As already mentioned, online disputes will only be registered where consumers fail to resolve their grievances after directly approaching businesses. As to concerns over a disparity in power between parties, the ODR system itself can assess this as a factor when determining a fair outcome for the parties and this may be achieved by programming artificial intelligence through specific algorithms.

\section{4 \\ ARTIFICIAL INTELLIGENCE AND ONLINE DISPUTE RESOLUTION}

This section briefly examines $\mathrm{Al}$ and its applicability to ODR. Information technology and artificial intelligence have paved the way for previously impossible new process structures to exist. ${ }^{80}$ Sourdin argues that $\mathrm{Al}$ and technology have reshaped the justice system in the form of three main types of new technology: first, supportive technology, which seeks to assist and advise those in the justice system; secondly, replacement technologies that replace the functions of humans; and finally, disruptive technologies, which focus on how technology may change existing roles. ${ }^{81}$ This indicates that $\mathrm{Al}$ may operate with or without human intervention.

In terms of the law, Zeleznikow submits that Al may fulfil a support role in legal decision-making by representing and processing information and, in doing so, supplementing human knowledge management skills with computer-based means. ${ }^{82}$ Barnett and Treleaven submit that there are two main branches of Al technology that have their own further subcategories: the first comprises knowledge-based systems, involving rule-based systems or case-based reasoning; and the second branch involves machine learning. ${ }^{83}$ Knowledge-based systems are based on computers that are programmed to reason and make use of expert knowledge in their decisionmaking process, whereas machine-learning systems rely on programming that has the ability to learn without explicit programming, and that can change or learn when it receives new data.

As these systems are based on data, they use information received from the Internet or uploaded onto their systems. Much will also depend on the coding of its algorithms. The processing of language and machine learning are therefore specific applications of artificial intelligence, which involve the process of examining words and phrases and enabling computers to learn to optimise certain tasks without the benefit of explicit rules-based programming. ${ }^{85}$ Machine learning is dependent upon the data it receives and therefore will be more accurate over time once more data is processed by

80 Sela 2018 Ohio State Journal on Dispute Resolution 9194.

81 Sourdin "Judge V Robot? Artificial Intelligence and Judicial Decision-Making" 2018 University of New South Wales Law Journal 11141117.

82 Zeleznikow 2017 International Journal for Court Administration 3035.

83 Barnett and Treleaven 2018 The Computer Journal 399402

84 Ibid.

85 Alarie, Niblett and Yoon "How Artificial Intelligence Will Affect the Practice of Law" 2018 University of Toronto Law Journal 106115. 
the system. ${ }^{86}$ From this, it is clear that machines can perform the same role as certain adjudicators because they learn from their experiences, depending on the amount of data they receive in respect of particular matters.

From the above analysis, it is apparent that while ODR may use the Internet as a medium to resolve disputes, Al decision-making systems may also be used in conjunction with ODR by using expert systems programmed by experts in the field and which possess rule-based algorithms. ${ }^{87}$ As Al has become more complex in problem-solving, machine-learning experts have developed tools that rely on data to identify certain patterns in a specific area by identifying the components that a system receives and by developing algorithms that maximise its predictive accuracy. ${ }^{88}$

Given the ease and effectiveness of online communications, it is imperative to address whether the South African legal system could benefit from $\mathrm{Al}$ and the establishment of an e-dispute system for consumers. Thompson submits that an ODR system controlled by Al may use expert knowledge and intelligent questionnaires to provide claimants with different functions and guidance specific to their individual circumstances. ${ }^{89}$ This is a key facet of $\mathrm{Al}$ and ODR because, although Al relies on data from similar cases, it still needs to establish a unique resolution for each case based on the facts and issues. Various authors have argued that data and Al have demonstrated the ability to regulate disputes through data analysis and machine learning, which reduces risk, liability, cost and injustice, and allows for the possible handling of more complex disputes, in place of face-to-face alternative dispute resolution. ${ }^{90}$

One example of an ODR tool is automated negotiation, in which a human third-party negotiator is substituted by software-based decision making. ${ }^{91}$ ODR is understood to take a less formal approach to resolving online disputes by using an independent entity rather than a party to a dispute to resolve the issue and this can be done through automated negotiation, online mediation or online arbitration. ${ }^{92}$ While automated negotiation seeks to reach a settlement of a dispute by considering the proposals of both parties, online mediation uses a process where a neutral third party assists the parties to the dispute in an impartial manner to reach a voluntary agreement based on their issues but does not make any decision itself. ${ }^{93}$ This would be a fair resolution because the parties themselves establish an outcome through agreement and Al merely facilitates the process; but may also propose resolutions where the parties cannot themselves decide on an outcome.

86 Surden "Artificial Intelligence and the Law: An Overview" 2019 Georgia State University Law Review 1305 1314-1316. The quality and availability of this data is crucial in machine learning; where this is absent, the system cannot develop.

Sourdin 2018 University of New South Wales Law Journal 11141121

Alarie, Niblett and Yoon 2018 University of Toronto Law Journal 106116.

Thompson 2015 International Journal of Online Dispute Resolution 453.

Wing 2017 International Journal on Online Dispute Resolution 1618.

1 Rabinovich-Einy and Katsh in Wahab, Katsh and Rainey Online Dispute Resolution 41.

2 Cortes in Wahab, Katsh and Rainey Online Dispute Resolution 139143.

93 Vilalta in Wahab, Katsh and Rainey Online Dispute Resolution 116-117. 
It has been established that Al may be used in conjunction with ODR and this could prove to be beneficial in resolving disputes without the need for human intervention. Sourdin, however, argues that although there exists opportunities for Al technology to support judges and potentially supplant them, it is likely that Al may be confined to lower-level decision-making. ${ }^{94}$ Where disputes require complicated legal and moral judgments in the decision-making process, it is debatable whether algorithms can make the reasonableness determinations that are needed to make and justify such complex judgments. ${ }^{95}$ Where decisions may be complex, human intervention may be necessary, thus requiring a hybrid system of computer and human decision-making in terms of which Al will defer complex decisions to humans. ${ }^{96}$ Much will depend on how $\mathrm{Al}$ is coded to resolve online disputes. Algorithms that are carefully constructed and closely monitored have the power and potential to provide fast and fair online resolutions of consumer disputes: ${ }^{97}$ Al would use data from other similar cases along with its coding to resolve existing disputes. ${ }^{98}$ The intention should be to allow consumers and their suppliers to resolve standard or uncomplicated disputes through algorithms from the comfort of their homes and computers. ${ }^{99}$

ODR and Al can therefore work together to create an online platform for consumers to resolve their disputes. At the same time, human intervention will be necessary where matters require an in-depth analysis of legal principles or where the issues are too complex for the algorithm. Although in theory, ODR and Al appear to be a useful tool in consumer disputes, it is necessary to provide an example of a system that has been successfully used in practice. The example chosen for illustrative purposes is eBay's dispute Resolution Center.

\section{EBAY DISPUTE RESOLUTION MODEL}

eBay has created its own ODR system. ${ }^{100}$ Sela describes this online dispute system as "a questionnaire-based algorithmic expert system that performs the role of a mediator." ${ }^{101}$ eBay has studied the pattern of disputes and has developed a system that can handle a large volume of repetitive disputes at a low cost and thereafter also collect data through the process and prevent future issues and problems from recurring. ${ }^{102}$

eBay encourages consumers first to contact the supplier through the Resolution Center to try to resolve the problem. It lists various options that depend on what type of dispute is involved. If the problem relates to a bought item, there are different options to click, such as not yet having

\footnotetext{
Sourdin 2018 University of New South Wales Law Journal 11141118.

Condlin 2017 Cardoza Journal of Conflict Resolution 717723.

Surden 2019 Georgia State University Law Review 13051320

Schmitz 2018 Journal of Internet Law 37.

Condlin 2017 Cardoza Journal of Conflict Resolution 717744.

99 Condlin 2017 Cardoza Journal of Conflict Resolution 732. This is where the algorithms need to be coded in an intelligent way to assist consumer complaints.

100 See https://resolutioncenter.ebay.com/ (20 August 2019).

101 Sela 2018 Ohio State Journal on Dispute Resolution 91102.

102 Rabinovich-Einy and Katsh in Wahab, Katsh and Rainey Online Dispute Resolution 42.
} 
received the item, or receiving an item that does not match the seller's description. The webpage also provides useful links to consumers that allow them to better understand the dispute resolution process, including:

- how eBay Buyer Protection works;

- what to do when a buyer doesn't pay;

- cancelling a transaction;

- what to do when you don't receive an item or it is not as described;

- resolving buying problems;

- resolving selling problems; and

- reporting a problem with a buyer.

There is also a link to click if the problem is not specifically listed, which takes the consumer to the eBay help page, where consumers may type out their problem. ${ }^{103}$ The system uses mediation rather than arbitration as respondents have been unwilling to consent to the decision-making authority of an arbitrator; and arguably mediation was more likely to be acceptable to parties than arbitration. ${ }^{104}$ The mediation process is simple, comprising the following steps: ${ }^{105}$

1. When a complaint is received, the mediator e-mails the other disputant, providing information about the process of mediation and the project, and soliciting basic information about the dispute. The mediator also inquires about the willingness to mediate.

2. Each party then has an opportunity to present their claims and what they wish the outcome to be.

3. The mediator attempts to resolve basic issues and problems of the dispute. This may require repeated communications with the parties, generally with the purpose of allowing the mediator to refine the stories and posit certain facts.

4. Most disputes that follow this process result in one party accepting a claim or result in a compromise. This comes about through the mediator's facilitation of discussion and responses, and his or her reformulation of the dispute and claims of each party.

5. In instances where there is no determinative resolution, the disputes are considered at an impasse and are largely left dormant (or to the devices of the parties themselves).

The system also relies on processing big data to assist the parties in identifying the problem, and thereafter to generate resolution options that both parties are likely to accept. ${ }^{106}$ The data it receives from past disputes is

103 See https://www.ebay.com/help/home.

104 Katsh, Rifkin and Gaitenby "E-Commerce, E-Disputes, and E-Dispute Resolution: In the Shadow of 'eBay Law'” 2000 Ohio State Journal on Dispute Resolution 705 709. The authors further explain that a single mediator is used to ensure consistency in decisions, and parties were separated by using email as a means of communicating information between the parties.

105 Katsh, Rifkin and Gaitenby 2000 Ohio State Journal on Dispute Resolution 705710.

106 Sela 2018 Ohio State Journal on Dispute Resolution 91103. 
helpful in providing resolutions for future cases. The coding of its algorithms is also important in predicting what outcome the parties are trying to reach.

EBay's ODR system has been hailed as a success by many consumers and authors because of its simple feedback system. ${ }^{107}$ Its success is attributed not only to speed and low cost in handling disputes, but also to the fact that it is able to resolve a large number of disputes, using an ODR system that recognises patterns from comparable disputes and matches them with effective proposed resolutions. ${ }^{108}$ As a result of this system, consumers may post a negative review that allows for a response from a business in order to avoid negative "publicity". ${ }^{109}$ The online system, therefore, has the effect of engaging businesses to respond to and resolve consumer complaints. Another reason eBay's success is that it handled over 60 million online disputes in a year with a 90 per cent success rate without human involvement. ${ }^{10}$ This is a remarkable number of disputes; the ordinary courts certainly cannot cater for such a large number in such a short time. Ebay's ODR system therefore proves that $\mathrm{Al}$ and ODR can resolve consumer disputes; and the system itself can be very simple to regulate and use. South Africa could base its own legal e-dispute resolution system on the Ebay framework.

\section{AN E-DISPUTE RESOLUTION SYSTEM FOR SOUTH AFRICA}

Following on from the previous sections, this part of the article proposes the establishment of an e-dispute resolution system for South African consumers. In terms of section 69(c)(iii) of the CPA, referring a dispute to an ODR system could be interpreted as a referral to an alternative dispute resolution agent. As a consequence, and in light of section 70(c) of the CPA, an e-dispute resolution system falls within the definition of an alternative dispute resolution agent because it will be an entity providing conciliation, mediation or arbitration services to assist in the resolution of consumer disputes. As a starting point, consumers may follow a three-tier process to resolve their disputes:

1. The first step is to utilise the company's internal customer service channels.

2. The second step is to use an ODR system - either automated negotiation or online mediation.

3. The final step is to use an online arbitration system or other judicial process. ${ }^{11}$

The first step attempts to settle the matter without any legal interventions. This is the consumer's first course of action in trying to resolve the dispute. As mentioned above, eBay also encourages consumers to contact the

107 Hanriot 2015 McGill Journal of Dispute Resolution 1 15. The system allows for positive, neutral or negative reviews and allows businesses to respond to consumer complaints.

108 Cortes in Wahab, Katsh and Rainey Online Dispute Resolution 156-157.

109 Hanriot 2015 McGill Journal of Dispute Resolution 115.

110 Sela 2018 Ohio State Journal on Dispute Resolution 91 93-103.

111 Cortes in Wahab, Katsh and Rainey Online Dispute Resolution 158. 
company's customer service first in order to resolve any consumer issues. Where customer services cannot resolve the issue, the consumer may use the e-dispute resolution system. This also ensures that consumers have complied with the CPA, which requires a consumer first to exhaust all other available avenues in terms of national legislation, including the option of using an alternative dispute resolution agent, before approaching the courts.

The e-dispute resolution system could be made available on the Commission's website. ${ }^{112}$ A quick link can be made to appear on the website, which would then direct the user to the e-dispute resolution system. Consumers would need to create a profile on the system if it were the first time they are using it. Basic, accurate and updated information should be included in a consumer's profile so that the system can properly communicate to the parties throughout the dispute. The terms and conditions should also be made available to consumers, who must accept the terms of use. These terms will indicate that consumers agree to be bound to the provisions of ECTA and the CPA. Once the registration process has been completed, consumers should be able to login with their credentials. Once logged in, the e-dispute resolution system will ask various questions to determine the nature of the dispute and direct the consumer to the correct channel in order to resolve the dispute. It will be the responsibility of the disputing parties to upload the necessary information to process the dispute, such as a summary of the facts with key dates and the sum involved. An upload button should be made available for consumers to upload proof of transactions and communications between themselves and suppliers, as well as details such as names, contact information, nature of the dispute and the relief sought. The system would then communicate with the parties during the process as to what stage the dispute is at.

Scholars have argued that a successful online e-commerce cross-border dispute resolution system should include a number of structures. ${ }^{113}$

1. A set of standardised codes: in the South African context, this would be ECTA and the CPA. ECTA assists with determining when electronic agreements have come into existence and this will indicate when consumers may claim performance or institute action. ${ }^{114}$

2. An e-commerce redress structure: redress is provided for in the CPA in terms of refunds, repairs or replacement of goods and services.

3. Structures for common cases: goods sold but not delivered or orders not complied with. Here Al technologies may easily resolve common cases based on the facts provided by the parties.

4. Efficient and effective enforcement functions: the Commission and Tribunal will be central to consumer disputes if the online process cannot resolve the dispute.

Based on the above, a South African e-dispute resolution system would be similar to the eBay structure. It would be a website available to South African consumers who are able to use it to resolve consumer disputes. The system would make use of and be powered by Al technologies, but would also

12 See http://www.thencc.gov.za/.

113 Duca, Rule and Loebl 2012 Penn State Journal of Law \& International Affairs 59 76-77.

114 See $\mathrm{s} 22$ of ECTA. 
require human intervention where disputes are more complicated. It would therefore involve a process of mediation, which fulfils the requirement that ODR systems should be impartial towards the disputing parties. Consumers could upload their complaints and proof thereof onto this platform and the online system would identify the type of complaint and redress sought by the consumer by using the necessary algorithms. The system would thereafter attempt to mediate the dispute and provide the parties with a resolution. Mania submits that ODR systems may use different technological systems to mediate disputes, such as providing electronic chats, live video conferencing or communication via email. ${ }^{115} \mathrm{It}$ is submitted that both technological systems could be used for the South African model. Where parties have difficulty understanding the dispute resolution process or have questions about the system, live Al chat bots could be used to answer these questions. The email system should be used to inform parties about updates or outcomes of the dispute.

An important consideration is whether these resolutions are binding on the disputing parties. Schmitz acknowledges that the question of whether ODR system decisions should be binding on the parties has caused great debate in the area of consumer redress. ${ }^{116}$ Online mediation seeks to resolve disputes between the parties in a consensual manner, but such resolution is often non-binding. ${ }^{117}$ Although it has been submitted that an e-dispute resolution system would involve mediation, the predicament of binding resolutions could be bypassed by relying on the existing provisions of the CPA relating to alternative dispute resolution. Similar to section $70(3)(a)-(b)$ and section 70(4), in terms of which the system successfully resolves the consumer's dispute, the system may record the resolution in the form of an order and, if the parties to the dispute consent to the order, it can be sent to the Tribunal or High Court to be made a consent order, which may include an award of damages in favour of the aggrieved consumer. The Act also mentions an accredited industry ombud or consumer courts and these also have potential to offer assistance in the future. Their role would have the effect of causing the resolutions to be legally binding on the parties. In terms of enforcement then, the consumer would be allowed to enforce this order in the Tribunal or courts if the other party fails to comply.

As a consequence, parties should be allowed to appeal or review the resolution. Again, the CPA may come to the assistance of consumers or suppliers by allowing them to appeal or review the outcome by using the Tribunal or consumer courts. Of course, this means that costs will be higher and the time to resolve the dispute may be longer. The main idea is to provide parties with a form of appeal or review process to ensure fairness is maintained.

115 Mania 2015 International Comparative Jurisprudence 7679.

116 Schmitz 2018 Journal of Internet Law 3 5. The author argues that parties are assured to gain access to remedies where decisions are made as a final determination between the parties, but in terms of arbitration, these decisions should be left to industry ombuds or consumer courts. This will be crucial to consumers because they may pursue an action where they know the outcome will be made as a final determination. Industry ombuds and the consumer courts as stated in the CPA could therefore strengthen an e-dispute resolution system by assisting with the outcomes of these disputes.

117 Mania 2015 International Comparative Jurisprudence 7679. 
If a dispute appears to be too complicated or cannot be resolved using the information uploaded by the parties, the e-dispute resolution system would allow consumers to direct the complaint to the correct redress mechanism in the form of the Commission, industry-accredited ombud, consumer court or Tribunal. This is also in line with section 70(2) of the CPA, which states that if there is no reasonable probability of the parties resolving their dispute, the alternative dispute resolution agent may terminate the process by notice to the parties, and the party who referred the matter to the agent may file a complaint with the Commission. This would ensure that the parties still have recourse to redress, although the process would now take longer depending on which protective body was used.

A key consideration is that the e-dispute resolution system must ensure access to justice for all consumers. As stated earlier, ODR is supposed to be cheaper and faster than traditional court action. In this case, the services should be free for anyone to use. However, perhaps a small and reasonable service fee could be charged to assist with maintenance of the system. All that should be required is access to the Internet. An impediment to access to justice would be that many disadvantaged consumers do not have access to computers or the Internet. To resolve this issue, the e-dispute resolution system could use mobile devices connected to wireless networks or that have data loaded onto sim cards. This would allow consumers to log onto the e-dispute resolution website from their phones and access the system to lodge their disputes. Arguably, not all consumers have cellular devices that can access the Internet. The final proposal would be to establish computer systems in some major retail stores that require consumers to go in store and use these facilities to complete the online process. This would then allow consumers without Internet devices to access e-dispute resolution in certain retail stores. This then fulfils the requirement that ODR systems be effective in ensuring that the system is accessible and easy to use.

A final consideration to ensure smooth functioning of the system is to create online guides that inform consumers about their rights, evidentiary obligations, procedural steps, and likely outcomes of the complaints process, so that they know what they are getting into when they use the system. ${ }^{118}$ This fulfils the transparency requirement under the general standards of ODR systems as argued by authors. Once consumers have all the relevant information at their disposal, they can make an informed decision on whether to use the e-dispute resolution system. This is particularly useful for consumers who are not prone to using online services, but who would like to use the system to resolve their disputes.

Other factors discussed in the general principles or standards for ODR systems pertain to time and privacy. Depending on the complexity of a dispute, the Al should be able to predict an expected timeline of the dispute. At all times, the system should keep the parties updated and the predicted time of resolving the dispute. Since ODR is supposed to be quicker than the court system, it should aim to resolve disputes in a matter of days. Of course, this depends on the assistance of both parties and the information and evidence uploaded by them. In terms of privacy, their information and

118 Schmitz 2018 Journal of Internet Law 37. 
claims should be kept confidential, unless they have consented to their information being publicised. The e-dispute resolution system therefore meets the standards of ODR systems because it is premised on the fundamental principles of ODR.

\section{CHALLENGES AND POSSIBLE LEGISLATIVE SOLUTIONS}

Proposing an ODR system is easy in theory but several challenges may exist in implementation. Besides financial and practical obstacles, there are often significant legal barriers to resorting to courts in disputes resulting from cross-border or online interactions, especially in identifying which court has jurisdiction to hear a case and which law should be applied. ${ }^{119}$ This is an important statement because consumers who purchase goods online prefer an online process for achieving redress rather than pursuing litigation with the seller, who may be based in another country. ${ }^{120}$ Scholars have argued that, by building resolutions directly into websites, as opposed to having them imposed by a judicial authority, ODR can be an efficient and flexible mechanism for handling e-commerce disputes, both at the domestic level and across borders because it works as the Internet does. ${ }^{12}$

Fortunately, ECTA may help address certain online issues pertaining to ODR. The ECTA has several objectives, including promoting legal certainty in respect of electronic communications and transactions; ${ }^{122}$ promoting technology neutrality in the application of legislation to electronic communications and transactions; ${ }^{23}$ and developing a safe, secure and effective environment for consumers and businesses to conduct and use electronic transactions. ${ }^{124}$ Section 90 provides for the jurisdiction of the courts. It states:

"A court in the Republic trying an offence in terms of this Act has jurisdiction where-

(a) the offence was committed in the Republic;

(b) any act of preparation towards the offence or any part of the offence was committed in the Republic, or where any result of the offence has had an effect in the Republic;

(c) the offence was committed by a South African citizen or a person with permanent residence in the Republic or by a person carrying on business in the Republic; or

(d) the offence was committed on board any ship or aircraft registered in the Republic or on a voyage or flight to or from the Republic at the time that the offence was committed."

119 OECD https://www.oecd.org/sti/consumer/36456184.pdf 8. The OECD highlights the costs and practical difficulties associated with filing cross-border claims, and that court procedures are beyond the financial means of most consumers with low-value disputes.

120 Zeleznikow "The Challenges of Using Online Dispute Resolution for Self-Represented Litigants" 2020 Journal of Internet Law 36.

121 Duca, Rule and Loebl 2012 Penn State Journal of Law \& International Affairs 5963.

122 S 2(1)(e) ECTA.

123 S 2(1)(f) ECTA.

124 S 2(1)(j) ECTA. 
One may apply this section to ODR where the parties have a dispute and the consumer is a South African citizen or the dispute arose in South Africa. Cross-border transactions will therefore be catered for by ECTA, but the ODR system should also stipulate in its terms and conditions of use that parties agree to be bound by the provisions of ECTA. This would also allow other enforcement agencies to have jurisdiction should the matter not be resolved through dispute resolution and then be referred to the Tribunal or courts. Scholars have indicated that ODR is also cross-jurisdictional and does not rely on any single set of laws or regulations. ODR thus resolves issues regarding the global nature of the Internet and is beneficial to both parties when they are aware of the fair and quick resolution process. ${ }^{12}$

Once the issue of jurisdiction has been resolved, the next issue relates to enforceability - that is, the ability to enforce a decision that has been made in favour of the consumer. ${ }^{126}$ Jurisdiction and enforceability would be facilitated if suppliers were to subscribe to and be bound by the e-dispute resolution system. This would entail suppliers registering as members of the system and therefore agreeing to be bound by the provisions of the CPA and ECTA. For example, the more common online providers of goods and services, such as Takealot, NetFlorist, Superbalist and OneDayOnly, could join the system and consumers would have a centralised mechanism to resolve their disputes. It must also be remembered that other retailers could also register, even if they do not offer online goods or services, because it allows consumers to resolve their disputes more quickly and efficiently. ECTA may also assist consumers and suppliers with clear enforcement rules. If the AI ODR system were to abide by ECTA, certain information needs to be disclosed by suppliers. This information includes, but is not limited to:

- physical address (including the address where legal documents may be served);

- email address;

- the return, exchange and refund policy of the supplier; and

- any alternative dispute resolution code to which that supplier subscribes and how the code may be accessed electronically by the consumer. ${ }^{127}$

This information is needed when trying to enforce a judgment or ruling against a supplier. Furthermore, ECTA states that a supplier must use a payment system that is sufficiently secure with reference to accepted technological standards at the time of the transaction and the type of transaction concerned. ${ }^{128}$ Although this payment provision addresses the payment method consumers would use to buy goods online, suppliers could use the same system to pay any damages or other payment to consumers who have suffered a loss.

When analysing the practicalities of an ODR system, a big concern relates to procedural fairness and whether the process remains neutral, impartial

\footnotetext{
Duca, Rule and Loebl 2012 Penn State Journal of Law \& International Affairs 5963.

6 OECD https://www.oecd.org/sti/consumer/36456184.pdf 29.

127 See the full list of required information s 43(1)(a)-(r) ECTA.

128 S 43(5) ECTA.
} 
and consistent in its decision making. ${ }^{129}$ On these issues, it is submitted that decisions made by Al software will largely depend on the data it receives. The disputing parties are therefore tasked with providing as much accurate information as possible in order for Al to make consistent and fair decisions. Importantly, the data that $\mathrm{Al}$ receives should also be processed and used in a fair manner. In other words, the data should not be used in a discriminatory manner, such as allowing a decision to be influenced by the financial means or age of the parties, unless this has a crucial impact on the case. The system should also ensure that it collects and processes information relating to both sides of the dispute in order to remain neutral and impartial.

Another challenge linked to procedural fairness may relate to the public access of courts as provided for in section 34 of the Constitution. Section 34 provides that "Everyone has the right to have any dispute that can be resolved by the application of law decided in a fair public hearing before a court or, where appropriate, another independent and impartial tribunal or forum". The challenge here is whether an ODR system can be operated without compromising the essential characteristics of courts in terms of independence, openness, fairness and accountability. ${ }^{130}$ It is clear that the Constitution does allow other forums to resolve disputes as long as they adjudicate on matters in a fair and independent manner. If the Al ODR system were to be regulated through the CPA and ECTA, this would ensure that the system would be independent and impartial because it would have to abide by these laws.

Mania has raised an important issue regarding the lack of physical meeting between the parties. The author submits that a lack of direct contact between disputing parties may cause a reduction in personal dynamics in the process; and a lack of mental connection between the parties may result in the dispute not being settled amicably. ${ }^{131}$ In other words, the absence of physical contact may make the parties less inhibited and they may say things they would not ordinarily say if they were in each other's presence because they can hide behind the safety of their computer. This is a difficult issue to resolve but it is proposed that if resolutions are binding on the parties, this would inform the parties that the process is to be taken seriously and that all information provided should be truthful - similar to providing information under oath in court. A clause would have to be provided in the terms and conditions of the AI ODR system to indicate that parties agree to provide accurate and truthful information, failing which a penalty may be imposed on the party in breach.

A final issue to consider is whether the parties to a dispute would have sufficient understanding of the legal nature and consequences of the dispute pertaining to legislation, cases and the ability to represent themselves without lawyers or a court's assistance. ${ }^{132}$ This is a crucial issue because

129 Abedi, Zeleznikow and Brien "Universal Standards for the Concept of Fairness in Online Dispute Resolution in B2C E-Disputes" 2019 Ohio State Journal on Dispute Resolution 357 367-370.

130 Zeleznikow 2020 Journal of Internet Law 34.

131 Mania 2015 International Comparative Jurisprudence 7679.

132 Zeleznikow 2020 Journal of Internet Law 37. 
lawyers often have the expertise to represent consumers in their disputes. To bypass this challenge, one could always have an Al-assisted legal advice system embedded in the ODR process. Consumers who face complex legal issues or who would like legal advice may click on a "legal advice" link that would then offer legal support. It must be remembered that an ODR system should be used with the support of human intervention; more complex cases should always allow human involvement where Al cannot resolve the dispute. This is also referred to as a decision support tool in that Al may be used to provide advice or Al may refer the matter for human intervention. ${ }^{133}$ In terms of the CPA, the matter may be referred to the Tribunal in order to be resolved.

A final consideration is the issue of expertise and resources. As already discussed, both the courts and consumer bodies lack the resources to process every consumer dispute. It is unclear what resources will be required to create and maintain an AI ODR system, but a certain amount of expertise will certainly be required to get the system up and running. Whether South Africa possesses the ability to create such a system with software experts or engineers is also unclear. As argued earlier, scholars have stated that it is crucial that Al ODR systems be created in a proper manner to ensure that they honour the core principles of fairness, impartiality and transparency.

As can be seen from the challenges above, and although many scholars have championed ODR, it does also create certain legal barriers. These challenges, however, could be overcome if the AI ODR system were created and regulated under the CPA and ECTA. A cross-border AI ODR system would work where resources are made available in terms of government agencies, online dispute resolution service providers and mechanisms for enforcing judgments. ${ }^{134}$ This would ensure that jurisdictional issues are resolved, as well as establish an authoritative body in the form of the Tribunal to adjudicate on matters that cannot be resolved through the online process. The normal provisions of the CPA would also apply to these online disputes so that disputing parties should be aware of what laws apply to refunds, replacements or repairs of goods and services.

\section{CONCLUSION}

Consumers are given various avenues to pursue redress in their disputes. However, consumers will only be successful if these avenues operate effectively. ${ }^{135}$ Where these avenues fail, consumers become disgruntled as they do not obtain redress as envisaged in the CPA. There are provisions that apply to online e-disputes that can fit under the alternative dispute resolution section of the CPA in respect of recording an order and enforcement. Both the CPA and ECTA could be crucial in regulating a South African e-dispute resolution system for consumers. It is submitted that ODR would prove beneficial for simple consumer disputes of any monetary value in that it would allow for a quicker and easier process to resolve such

${ }^{33}$ Zeleznikow Journal of Internet Law 312

134 Duca, Rule and Loebl 2012 Penn State Journal of Law \& International Affairs 5963.

135 Woker 2016 SA Merc LJ 28. 
disputes. Authors have argued that a system enabling consumers and suppliers to resolve disputes using the Internet (which they have used to purchase or sell goods and services) is a logical solution and extension of ecommerce. ${ }^{136}$

Al can have a profound effect on how commercial transactions are conducted and regulated. It is possible to rely on machine learning to process claims and help address consumer disputes. Although financial constraints may have been a major factor for consumers in deciding to pursue their claims, Al may now be used in such a way that it can enhance South African consumer laws and provide access to justice. A cost effective and simple approach is needed for the vast majority of consumer disputes to ensure access to justice for all.

136 Mania 2015 International Comparative Jurisprudence 7682. 